
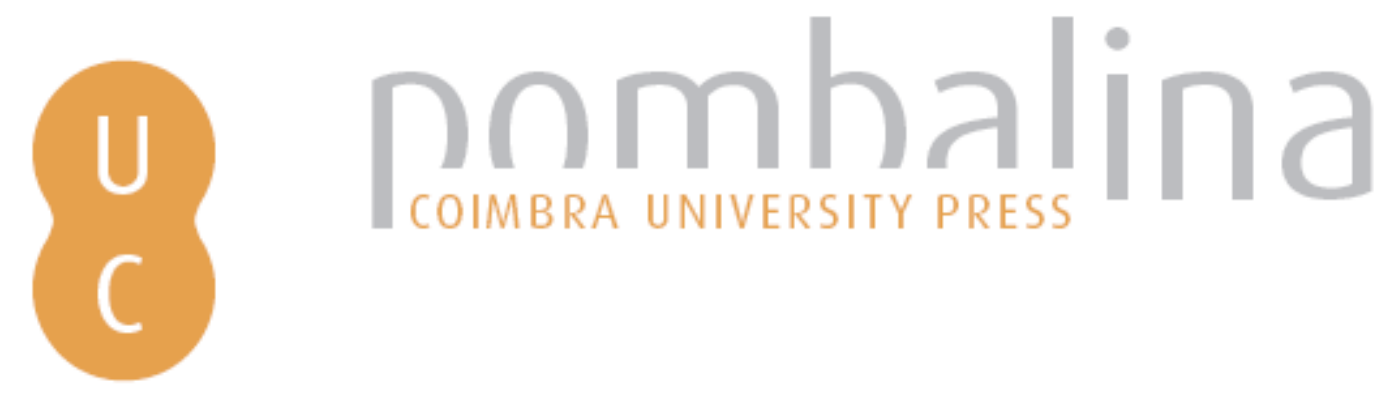

\title{
Avaliação da degradação hidromorfológica de canais como subsídio à gestão do risco de inundações urbanas: bacia dos rios Guaxindiba/Alcântara (Rio de Janeiro, Brasil)
}

Autor(es): $\quad$ Damasco, Fernando Souza; Cunha, Sandra Baptista da

Publicado por: Imprensa da Universidade de Coimbra; RISCOS - Associação

Portuguesa de Riscos, Prevenção e Segurança

URL

persistente:

URI:http://hdl.handle.net/10316.2/34848

DOI:

DOI:http://dx.doi.org/10.14195/978-989-96253-3-4_50

Accessed : $\quad$ 26-Apr-2023 09:05:28

A navegação consulta e descarregamento dos títulos inseridos nas Bibliotecas Digitais UC Digitalis, UC Pombalina e UC Impactum, pressupõem a aceitação plena e sem reservas dos Termos e Condições de Uso destas Bibliotecas Digitais, disponíveis em https://digitalis.uc.pt/pt-pt/termos.

Conforme exposto nos referidos Termos e Condições de Uso, o descarregamento de títulos de acesso restrito requer uma licença válida de autorização devendo o utilizador aceder ao(s) documento(s) a partir de um endereço de IP da instituição detentora da supramencionada licença.

Ao utilizador é apenas permitido o descarregamento para uso pessoal, pelo que o emprego do(s) título(s) descarregado(s) para outro fim, designadamente comercial, carece de autorização do respetivo autor ou editor da obra.

Na medida em que todas as obras da UC Digitalis se encontram protegidas pelo Código do Direito de Autor e Direitos Conexos e demais legislação aplicável, toda a cópia, parcial ou total, deste documento, nos casos em que é legalmente admitida, deverá conter ou fazer-se acompanhar por este aviso. 

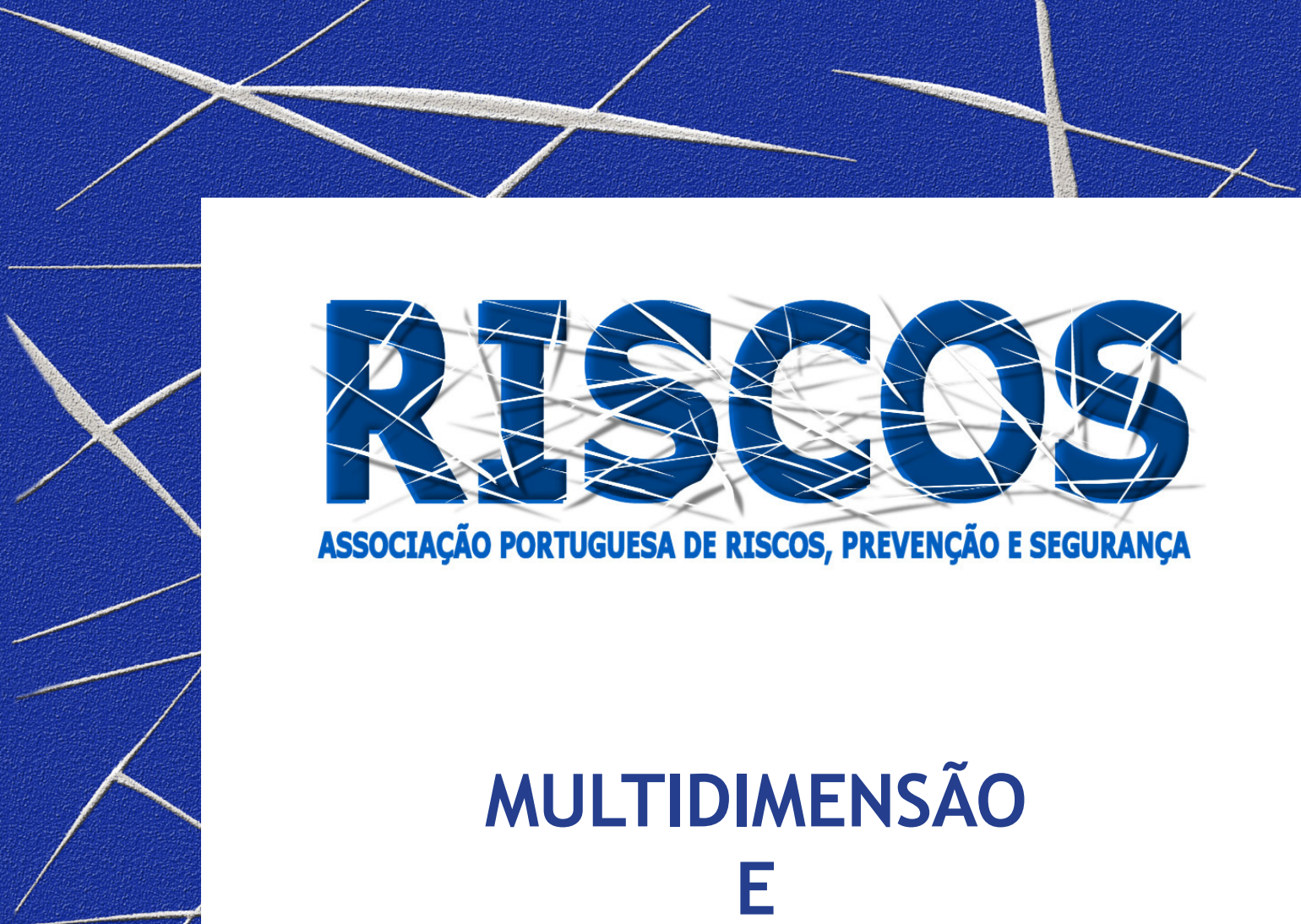

ASSOCIAÇÃO PORTUGUESA DE RISCOS, PREVENCCÃO E SEGURANÇA

MULTIDIMENSÃO

E
TERRITÓRIOS DE RISCO

III Congresso Internacional

I Simpósio Ibero-Americano

VIII Encontro Nacional de Riscos

Guimarães

2014 


\title{
AVALIAÇÃO DA DEGRADAÇÃO HIDROMORFOLÓGICA DE CANAIS COMO SUBSÍDIO À GESTÃO DO RISCO DE INUNDAÇÕES URBANAS: BACIA DOS RIOS GUAXINDIBA/ ALCÂNTARA (RIO DE JANEIRO, BRASIL)
}

\author{
Fernando Souza Damasco \\ Instituto Brasileiro de Geografia e Estatística (IBGE) \\ Programa de Pós-Graduação em Geografia, Universidade Federal Fluminense \\ (UFF, Brasil) - fernandodamasco@id.uff.br \\ Sandra Baptista da Cunha \\ Programa de Pós-Graduação em Geografia, Universidade Federal Fluminense \\ (UFF, Brasil) \\ Conselho Nacional de Desenvolvimento Científico e Tecnológico (CNPq) \\ sandracunha@openlink.com.br
}

\begin{abstract}
RESUMO
Esse trabalho se propõe a relacionar a degradação dos canais à ocorrência de inundações (flashfloods) na bacia dos rios Guaxindiba/Alcântara (Rio de Janeiro, Brasil). A mensuração da degradação dos canais abrangeu as estruturas do leito (desenvolvimento do canal e curso longitudinal); das margens (seções transversais); e da planície aluvial (uso da terra e faixa ciliar). A avaliação foi visual e consistiu na análise de trechos de $250 \mathrm{~m}$ a jusante e a montante de 7 pontes. Os dados colhidos foram quantificados e transformados em índices, que classificam os estágios de degradação em crítico, avançado, intermediário, inicial e natural. Concluiu-se que a bacia encontra-se em um estágio avançado de degradação hidromorfológica, marcada pela alteração brusca dos traçados dos canais, do leito, das margens, da faixa ciliar e da planície. Os índices, comparados aos dados de enchentes da Defesa Civil, sugerem que as áreas onde os canais estão mais degradados estejam também mais suscetíveis às inundações.

Palavras-chave: Inundações urbanas, degradação ambiental, ajustes nos canais, geomorfologia fluvial antrópica.

Introdução

Desde os anos 1960, muitos investigadores têm estudado as alterações nos rios por ações antrópicas, sobretudo na tentativa de elucidar as causas, características, localização e temporalidade dos efeitos ambientais concernentes às mudanças nos canais (Chin \& Gregory, 2005; Gregory, 2006; Rodrigues, 2010; Cunha, 2012, entre outros).

Localizada na borda leste da Baía de Guanabara e drenando uma superfície de $168,37 \mathrm{~km}^{2}$, a bacia em estudo é formada pela sub-bacia do rio Alcântara e pela sub-bacia do rio Guaxindiba e engloba grande parte do município de São Gonçalo e pequenos trechos dos municípios de Niterói e Itaboraí (figura 1).
\end{abstract}




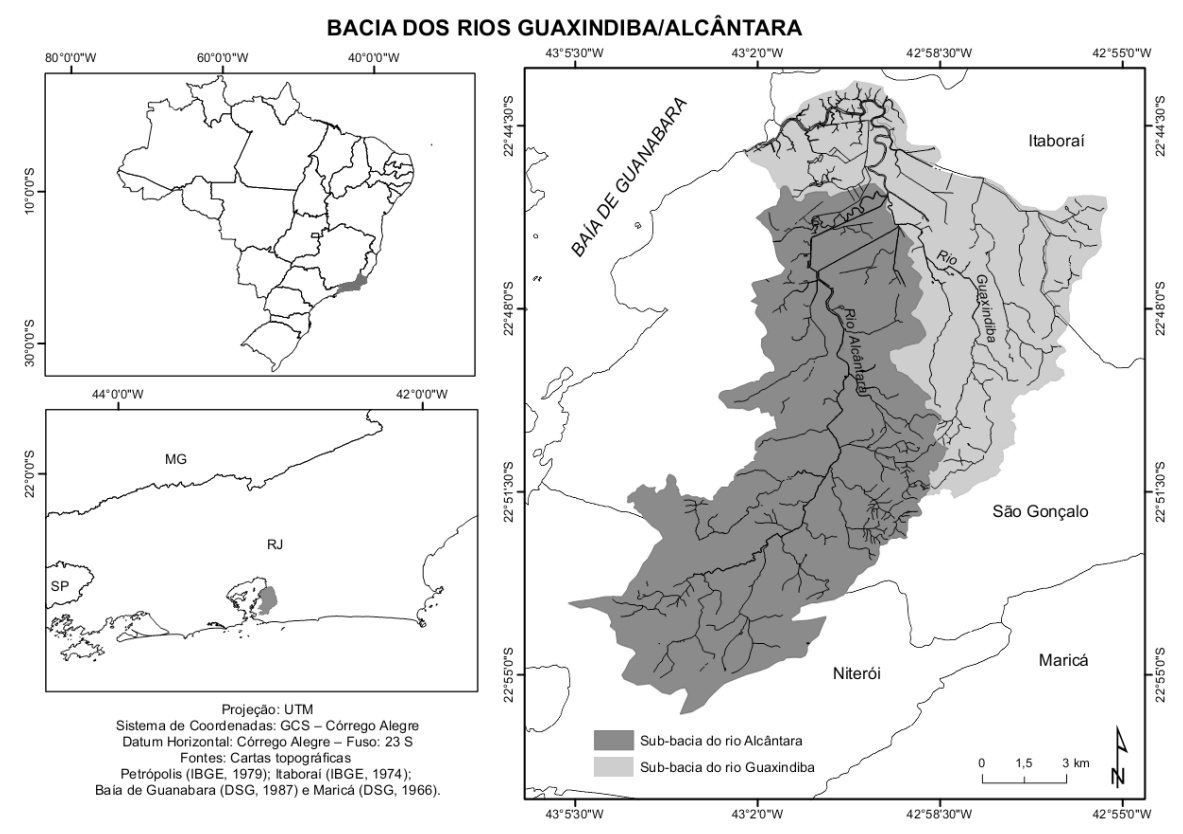

Figura 1: Localização da área de estudo.

Elaboração: Fernando Damasco, 2013.

\section{Materiais e métodos}

A mensuração da degradação do hidromorfológica dos canais pela ação antrópica abrangerá as três principais feições fluviais: 1) leito fluvial (desenvolvimento do canal fluvial, curso longitudinal, estruturas do leito fluvial); 2) margem fluvial (perfil transversal e estrutura das margens); 3) planície aluvial (uso da terra e faixa ciliar).

A avaliação foi realizada através de trabalhos de campo com base em metodologias desenvolvidas por agências ambientais de países referenciais em gestão de cursos d'água (Meier et al., 2012; Environment Agency, 2003; Barbour et al., 1999; Parsons et al., 2001) com as adaptações necessárias ao ambiente tropical. A avaliação foi visual e consistiu na análise, a partir de pontes, de 7 trechos de 250 metros do rio a jusante e a montante. 0 formulário de análise é composto por 21 parâmetros que são quantificáveis de 0 a 4, sendo que quanto mais próximo de 4, mais o canal se aproxima de suas condições naturais, quanto mais próximo de zero, mais degradado ele se encontra. Esses valores de referência foram definidos a partir da análise da bibliografia nacional e internacional sobre degradação de canais. A partir da média entre os parâmetros, chega-se a uma nota para o trecho, estabelecendo-se cinco classes de degradação hidromorfológica, conforme propõe Meier et al. (2012): crítico $(0,0-0,4)$, avançado $(0,5-1,4)$, intermediário $(1,5-2,4)$, inicial $(2,5-3,4)$ e natural $(3,5-4,0)$.

\section{Resultados e discussão}

Os resultados da análise hidromorfológica dos trechos selecionados indicam que a bacia do Guaxindiba/Alcântara apresenta 4 trechos caracterizados com estágio avançado de degradação 
hidromorfológica e dois trechos com estágio crítico. Os dados compilados encontram-se sumarizados na tabela I e espacializados na figura 2 . Os trechos 1 e 2 foram considerados os mais degradados, apresentando estágio crítico de degradação. 0 trecho 4, por sua vez, localizado mais a montante da bacia, é o trecho mais preservado, muito embora esteja classificado como intermediário. A média final por feição geomorfológica indica que as margens e a planície estão em estágio avançado de degradação.

Na sub-bacia do rio Alcântara, o leito vai se tornando mais degradado, quanto mais se aproxima da foz. O rio principal apresenta-se sinuoso no alto curso. No médio e baixo curso, devido às inúmeras retificações realizadas, o rio apresenta majoritariamente padrão reto. Ao longo dos rios, ocorrem diversas passagens chamadas pinguelas, por onde a população pode cruzar o curso fluvial. Muitas vezes, as pinguelas funcionam como caminhos em meio à mata ciliar, por onde a população consegue acessar o leito do rio, depositando todo tipo de lixo, desde sacolas com resto de alimentos até móveis e eletrodomésticos de dimensões consideráveis.

As soleiras (riffles) e depressões (pools) são observáveis apenas no alto curso dos rios. De acordo com Cunha (2003), nos rios naturais, as seções tendem a apresentar essas soleiras e depressões devido à sinuosidade do canal. Como nos rios desnaturalizados a sinuosidade desaparece, não ocorrem tais formações.

No baixo curso, o fluxo tende a se homogeneizar, apresentando-se normalmente laminar em toda a extensão do leito. Devido à quase ausência de fluxo observada no Canal Isaura Santana, desenvolveram-se muitas gigogas (Eichhornia crassipes) e tifas (Typha domingensis).

Tabela I: Resultados finais da análise hidromorfológica

\begin{tabular}{|c|c|c|c|c|c|c|c|c|c|}
\hline \multirow{2}{*}{ Feição } & \multicolumn{9}{|c|}{ Médias parciais por trecho } \\
\hline & 1 & 2 & 3 & 4 & 5 & 6 & 7 & Média & Estágio \\
\hline Leito & 0,7 & 0,9 & 2,0 & 2,5 & 2,3 & 1,7 & 0,7 & 1,5 & Intermediário \\
\hline Margens & 0,9 & 0,3 & 1,7 & 3,1 & 1,3 & 2,0 & 0,7 & 1,4 & Avançado \\
\hline Planície & 0,0 & 0,0 & 0,7 & 1,3 & 0,6 & 0,7 & 0,0 & 0,5 & Avançado \\
\hline Média final & 0,4 & 0,4 & 1,5 & 2,3 & 1,4 & 1,4 & 0,5 & 1,1 & Avançado \\
\hline Estágio & Crítico & Crítico & Avançado & Intermediário & Avançado & Avançado & Avançado & $x$ & $\mathrm{x}$ \\
\hline
\end{tabular}

Elaboração: Fernando Damasco, 2014. 


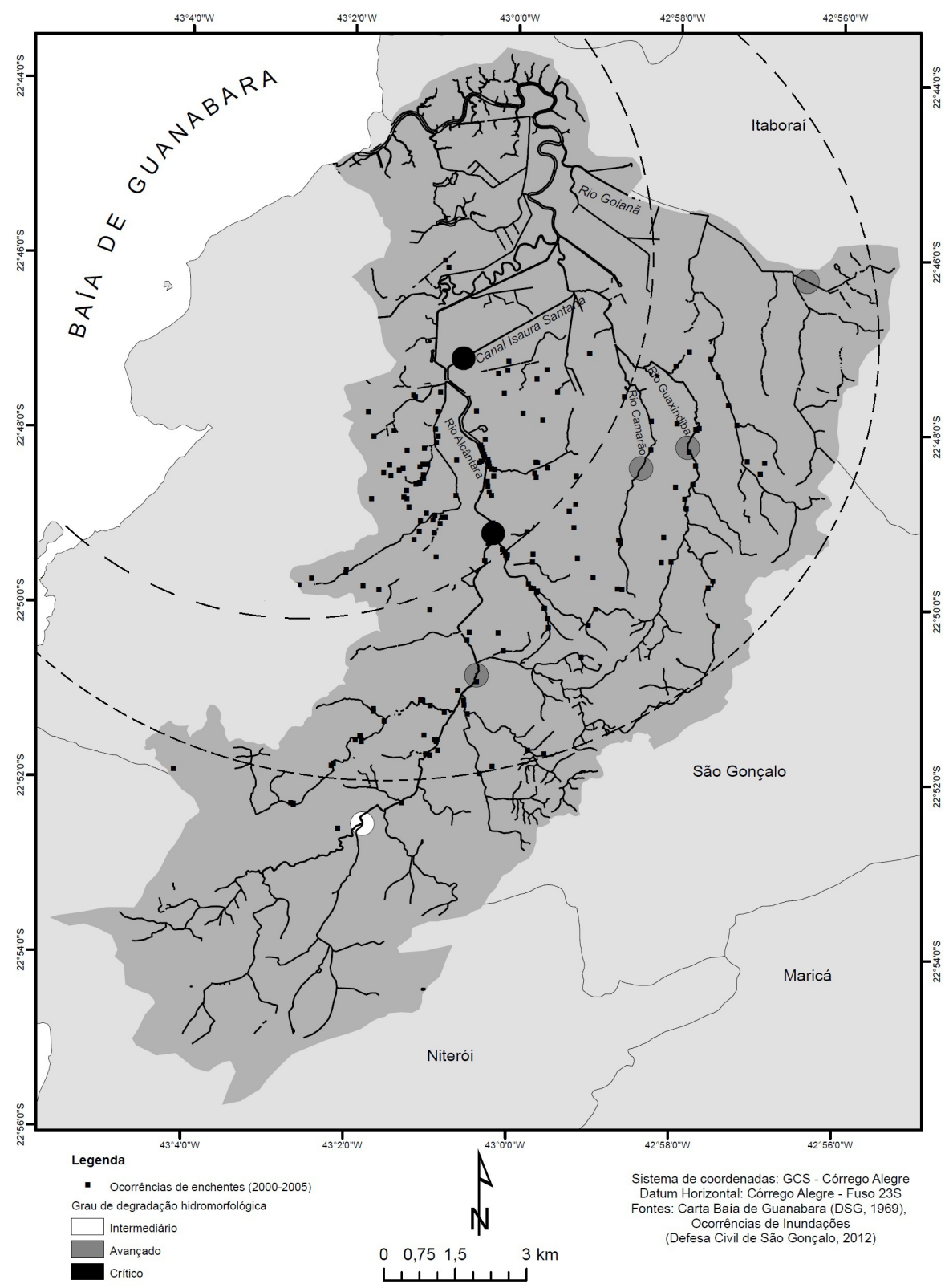

Figura 2: Degradação hidromorfológica dos canais e ocorrência de enchentes. Observe-se o caráter concêntrico dos graus de degradação em relação à Baía de Guanabara. Elaboração: Fernando Damasco, 2013. 
Em toda a rede hidrográfica, pode-se verificar a presença de muitos materiais que não fazem parte da dinâmica natural do leito fluvial, entre elas blocos de concreto, pedaços de tijolos, visivelmente sobras de construções. No canal principal, os sedimentos de fundo apresentam-se, na maioria dos pontos analisados, homogêneos, formados predominantemente por sedimentos finos.

A análise hidromorfológica das margens dos rios evidenciou a intensidade com a qual as estruturas antrópicas modificam o sistema fluvial, desequilibrando-o. Os resultados evidenciam em todos os pontos coletados a presença de pontes e tubulações que desestabilizam as margens e corroboram os processos erosivos. A pouca variabilidade da largura também é uma expressão de alteração da dinâmica natural de erosão e deposição do rio.

Os resultados revelam ainda o alto grau de comprometimento das planícies de inundação. Além de o uso da terra predominante ser urbano, a presença de estruturas negativas foi uma constante em todos os trechos observados. Essas estruturas podem ser fábricas poluidoras, lixões, tubulações, represas e barragens, estradas etc.

Em uma articulação com os dados espaciais de ocorrências de enchentes da Defesa Civil do Município de São Gonçalo (figura 2), pode-se inferir que as inundações concentram-se nas proximidades dos trechos com morfologia mais degradada.

\section{Conclusão}

Os rios da bacia do Guaxindiba/Alcântara encontram-se em um estágio crítico/avançado de degradação hidromorfológica, marcada pela alteração brusca nos traçados dos canais fluviais, das estruturas do leito, das margens, da faixa ciliar e de impermeabilização da planície adjacente.

A espacialização da degradação sugere uma lógica concêntrica em relação à Baía de Guanabara, o que traduz a própria diversificação morfológica da bacia. 0 alto curso, ainda bem preservado, com situação intermediária. Um médio curso bastante alterado e com estágio avançado de degradação. 0 quadro completa-se pelo baixo curso, completamente modificado, com os canais retificados e sem sinais da dinâmica natural do rio, onde a metodologia classifica a degradação como em estágio crítico.

Os resultados da análise hidromorfológica sugerem que o avanço do grau de degradação dos canais seja diretamente proporcional ao aumento da ordem hierárquica. Desse modo, as políticas de planejamento, gestão e manejo dos canais, que visassem a despoluição e a recuperação, deveriam partir dos canais de primeira ordem, até os de ordens mais elevadas.

O fato de as áreas mais suscetíveis às inundações estarem localizadas em áreas muito degradadas permite inferir que há uma relação direta entre a degradação e a suscetibilidade às inundações. Essa informação pode ser fundamental, de modo que as políticas de planejamento e prevenção de inundações deveriam considerar o conceito de degradação, dando especial ênfase à recuperação das áreas degradadas, de forma a devolver ao rio a sua dinâmica natural.

\section{Bibliografia}

Barbour, M. T.; Gerritsen, J.; Snyder, B.; Stribling, J. et al. (1999) - Rapid Bioassessment Protocols for Use in Streams and Wadeable Rivers: Periphyton, Benthic Macroinvertebrates, and Fish. U.S. Washington, D.C.: Environmental Protection Agency; Office of Water.

Chin, A.; Gregory, K. J. (2005) - Managing urban river channel adjustments. Geomorphology, 69: 28-45. 


\section{CAPÍTULO 3.2: RISCOS CLIMÁTICOS E HIDROLÓGICOS}

Cunha, S. B. (2003) - Canais fluviais e a questão ambiental. In: Cunha, S. B.; Guerra, A. J. T. (orgs.). A questão ambiental: diferentes abordagens. Rio de Janeiro: Bertrand Brasil.

Cunha, S. B. (2012) - Rios desnaturalizados. In: Barbosa, J. L. \& Limonad, E. (orgs.) Ordenamento territorial e ambiental. Niterói: Editora da UFF.

Environment Agency (2003) - River Habitat Survey Manual: 2003 version. Disponível em: http://www. environment-agency.gov.uk/, acesso em 16/07/2013.

Gregory, K. J. (2006) - The human role in changing fluvial systems: retrospect, inventory and prospect. Geomorphology, v. 79, 172-191.

Meier, G.; Zumbroich, T.; Roehrig, J.; Souvignet, M. (2012) - Application of the radiating effect concept to implement measures stipulated by the European Water Framework Directive. Water Science \& Technology, 66: 2793-2799.

Parsons, M.; Thoms, M.; Norris, R. (2001) - Australian River Assessment System: AusRivAS Physical Assessment Protocol. Camberra, Australia: Environment Austrália.

Rodrigues, C. (2010) - Avaliação do impacto humano da urbanização em sistemas hidro-geomorfológicos. Desenvolvimento e aplicação da metodologia na Grande São Paulo. Revista do Departamento de Geografia, Universidade de São Paulo, 20: 111-125, 2010. 